\title{
PYROLYSIS OF METHANE IN A SUPERSONIC, ARC-HEATED FLOW
}

\author{
F.K. Lu, ${ }^{*}$ C.M. Roseberry, ${ }^{\dagger}$ J.M. Meyers ${ }^{\ddagger}$ and D.R. Wilson ${ }^{\S}$ \\ University of Texas at Arlington, Arlington, Texas 76019 \\ and \\ Y.M. Lee \\ MSE Inc., Butte, MT 59702 \\ and \\ P.A. Czysz** \\ Hypertech Concepts, St. Louis, MO 63141
}

\begin{abstract}
An arc heated facility was modified to allow arc pyrolysis of methane at supersonic conditions, representative of conditions in the reformer location of an aibreathing hypersonic vehicle. The rationale for arc pyrolysis is provided. Major modifications to the facility include a diagnostic chamber and a carbon cold trap. Preliminary results indicate the feasibility of arc pyrolysis of methane.
\end{abstract}

\section{Introduction}

$\mathrm{T}$ he high specific enthalpy of combustion of hydrogen makes it a desirable fuel for hypersonic airbreathing vehicles, such as space access and global reach vehicles. ${ }^{1,2}$ Hydrogen allows better propulsion efficiencies, resulting in longer ranges and higher speeds, compared to hydrocarbon fuels. Unfortunately, the low density of the fuel results in excessive tankage, which adversely affects the overall vehicle design. At around its boiling point of $20 \mathrm{~K}$ at $1 \mathrm{~atm}$, liquid

*Professor of Mechanical and Aerospace Engineering and Director, Aerodynamics Research Center, Assoc.

Fellow AIAA

${ }^{\dagger}$ Graduate Research Associate, Member AIAA.

${ }^{\sharp}$ Research Associate, Aerodynamics Research Center; presently, Diploma Course Student, Von Karman Institute for Fluid Dynamics, Rhode-Saint-Genèse, Belgium, Student Member AIAA.

${ }^{\S}$ Professor of Mechanical and Aerospace Engineering, Assoc. Fellow AIAA.

"Staff Engineer/Program Manager, Senior Member AIAA.

${ }^{* *}$ President, Assoc. Fellow AIAA.

Copyright (C) 2004 by the American Institute of Aeronautics and Astronautics, Inc. All rights reserved. hydrogen has a density of $70.8 \mathrm{~kg} / \mathrm{m}^{3}$. Thus, storing $\mathrm{LH}_{2}$ requires bulky tanks that negatively affect the vehicular weight, size and, indirectly, drag. A vicious cycle that yields a massive structure may ensue, resulting in a marginal payload capability.

On the other hand, while hydrocarbon fuels do not have the enthalpy of reaction of hydrogen, their higher density drastically reduces the tank volume. But, a purely hydrocarbon-fueled vehicle may not be capable of orbital flight. ${ }^{3}$ Studies have indicated that there is a potential tradeoff in using hydrocarbon fuels despite their lower energy density. The solution to this quandary of size, weight and energy density appears to be fuel reformation or pyrolysis, where the hydrogen is carried aboard the vehicle as a hydrocarbon. The hydrocarbon is then reformed or cracked to produce hydrogen. The hydrocarbon of choice is methane because of its highest hydrogen-to-carbon ratio. The reduction in vehicular size is illustrated schematically in Fig. 1, where the relatively large hydrogen-fueled vehicle is obvious. Moreover, the strongly endothermic reforming or pyrolytic reaction has a potential benefit as part of an active cooling system. Hence, fuel reformation or pyrolysis may constitute a part of an overall hypersonic vehicle design. ${ }^{5,6}$ 


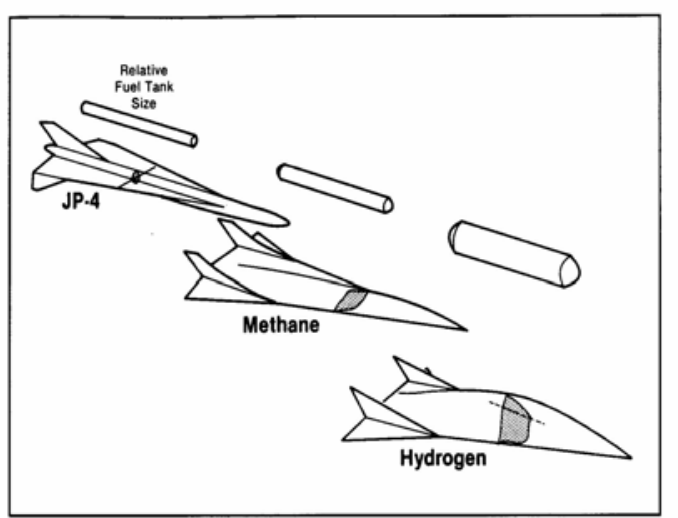

Fig. 1. Effect of fuel selection on hypersonic vehicle size. ${ }^{4}$

Aerospace application of hydrogen reforming can exploit developments in terrestrial, hydrogen reforming and pyrolysis, greatly spurred recently by the desire to develop a "hydrogen economy." The direct production of hydrogen from water remains the ultimate goal. However, the general wisdom at present is to make use of intermediate or bridge technologies, requiring the production of hydrogen from hydrocarbon or carbon sources.

\section{Brief Review of Pertinent Industrial Hydrogen Produc- tion Technologies}

Hydrogen at present is almost used exclusively as an industrial material instead of as a fuel. Amongst various hydrogen production technologies, ${ }^{7}$ steam reformation and thermal cracking appear to be suitable for hypersonic airbreathing propulsion applications. Steam methane reforming (SMR) at present is the cheapest way of producing hydrogen and is subject to numerous, continued development. $^{8}$ SMR dominates current hydrogen production, accounting for roughly 50 percent of the world's annual output. In steam reformation, a light hydrocarbon feedstock, usually methane (natural gas) due to its high hydrogen-to-carbon ratio, reacts catalytically with steam at elevated temperatures to produce hydrogen and carbon oxides. For example, a mixture of hydrogen and carbon monoxide, known as syngas, may be produced

$$
\mathrm{CH}_{4}+\mathrm{H}_{2} \mathrm{O} \rightarrow \mathrm{CO}+3 \mathrm{H}_{2} \quad \Delta H^{0}=206 \mathrm{~kJ} / \mathrm{mol}
$$

This process operates at around $700-1000 \operatorname{deg} \mathrm{C}$ at pressures of about 0.3-2.5 MPa. The steam plays an important role in preventing graphite deposition on the catalyst at the elevated SMR temperature. A further water-gas shift exothermic reaction

$$
\mathrm{CO}+\mathrm{H}_{2} \mathrm{O} \rightarrow \mathrm{CO}_{2}+\mathrm{H}_{2}
$$

converts the carbon monoxide into carbon dioxide. The energy released from this reaction can however not be directly used for the reformation. The carbon dioxide is removed via absorption or membrane separation. The gas mixture is further cleaned to remove other unwanted components. The leftover gas consisting of about 60 percent combustible constituents $\left(\mathrm{H}_{2}, \mathrm{CH}_{4}, \mathrm{CO}\right)$, along with a portion of the primary gas itself, is used to fuel the reformer. The entire process, which includes feedstock desulfurization and steam production, is energy intensive, requiring 30-35 percent of the natural gas to be consumed as fuel.

Steam reforming of methane has also been proposed for hypersonic propulsion applications. ${ }^{9}$ However, it is a poor solution. ${ }^{10}$ Although water is a good energy absorption medium, it has no combustion energy. Reactions (1) and (2) indicate a large proportion of water has to be carried onboard. Interestingly, under some circumstances, carriage of methane and water may actually lead to a reduction in tank volume compared to $\mathrm{LH}_{2}$. On the other hand a disadvantage of methane reformation is the ultimate production of carbon dioxide which, in addition to being a greenhouse gas, complicates the design of the reformer and combustion flowpath.

In thermal cracking or pyrolysis, methane is decomposed thermally, without oxidation, at temperatures up to 1400 deg C to separate hydrogen from carbon with trace quantities of other hydrocarbons. ${ }^{11,12}$ Ideally,

$$
\mathrm{CH}_{4} \rightarrow \mathrm{C}+2 \mathrm{H}_{2} \quad \Delta H^{0}=75.6 \mathrm{~kJ} / \mathrm{mol}
$$

that is, one mole of methane yields two moles of hydrogen. Carbon is deposited as carbon black (graphite), a valuable byproduct that can be used in tire production, as a reducing material in metallurgic industries, inks and toners, pigmenting, ultraviolet stabilizing and electrical conducting agent amongst various other uses. Thermal cracking can be potentially catalyzed by carbon felt. ${ }^{11}$ The ability to sequester carbon (instead of carbon dioxide production in SMR) is environmentally advantageous. Moreover, this process is mildly endothermic at $37.8 \mathrm{~kJ} / \mathrm{mol} \mathrm{H}_{2}$, which is less than that required for SMR. In commercial applications, it is estimated that an additional 10 percent of the methane need to be combusted to drive the process.

There are some related developments of thermal cracking that serve as background to the present study. The first is the Kvaerner Carbon Black \& Hydrogen Process, which was first placed in commercial production in June 1999. This is a plasma arc process which operates at 1600 deg $\mathrm{C}$ to separate carbon and hydrogen. ${ }^{13-15}$ This process was initially geared for producing carbon black and is emission free, compared to traditional methods which are extremely polluting. (The production of carbon nanotubes remains an intriguing possi- 
bility ${ }^{16}$ ) The byproduct from this process is hydrogen that is burnt. However, the Kvaerner has been suggested for hydrogen production. In the modified process, the heat for splitting the feedstock is supplied by a plasma burner, which utilizes recycled hydrogen from the process as a plasma gas. A heat exchanger heats up the process flow. A large amount of energy, in excess of about double the theoretical minimum is required because of the high reaction temperature. The surplus energy can, to a certain degree, be recycled in the form of steam. For raw material, this process may utilize hydrocarbon compounds ranging from light gases to heavy oil fractions. ${ }^{17}$

A plasma reformer has been developed at the Massachusetts Institute of Technology (MIT), similar to the Kvaerner process. The MIT "Plasmatron" can operate at temperatures of over $2000 \mathrm{deg} \mathrm{C}$ and can yield $80-90$ percent hydrogen. It can also operate as a steam reformer. The main advantage of plasma technology is that it allows for a compact and lightweight design because of the rapid reaction. The disadvantage is that it is dependent on electrical power. ${ }^{18,19}$ The MIT plasmatron has even been installed onboard road vehicles. ${ }^{20}$

Finally, another related plasma-based hydrogen production technology that apparently is solely used as a steam reformer is a so-called rotarc reactor, ${ }^{21,22}$ itself based on a glidarc reactor.$^{23}$ These processes make use of a cold plasma of about $1000 \mathrm{~K}$ to produce syngas from hydrocarbons through a non-equilibrium process. It is thought that the cold plasma allows different chemical reactions to be stimulated, different from conventional combustion. $^{24}$

Bruno and Cyzsz ${ }^{10}$ have proposed that thermal arc processing of a hydrocarbon at high temperatures in the absence of water or oxygen, such as in a low current, high voltage, high pressure arc heater, can decompose the hydrocarbon into separate hydrogen and carbon streams. Carbon disposal may also be facilitated as the carbon stream impinges a cold trap.

The potential for high conversion efficiency and a compact, lightweight design arising from thermal arc pyrolysis are advantages for in-flight pyrolysis of methane. For example, the AJAX hypersonic flight vehicle concept involves the reformation of hydrocarbon fuels such as methane into hydrogen and carbon. ${ }^{25,26}$ The high energy density of hydrogen is available for combustion while still achieving the volumetric efficiency of much heavier hydrocarbon fuels. At these conditions, the carbon produced in the reformation process can also be burned in the supersonic combustion chamber.

It is envisaged that electrical power for operating an in-flight arc heater would be obtained by tapping part of the output of the MHD generator in an AJAX-type hypersonic vehicle. ${ }^{10,27-29}$ This study focuses on the ex- perimental demonstration of the feasibility of pyrolysis of methane via a non-equilibrium plasma process. Thus, no consideration is placed on the overall system design. The specific objectives of the investigation are to modify an arc heater facility to deliver methane, to develop a reactor and to demonstrate the feasibility of arc pyrolysis of methane.

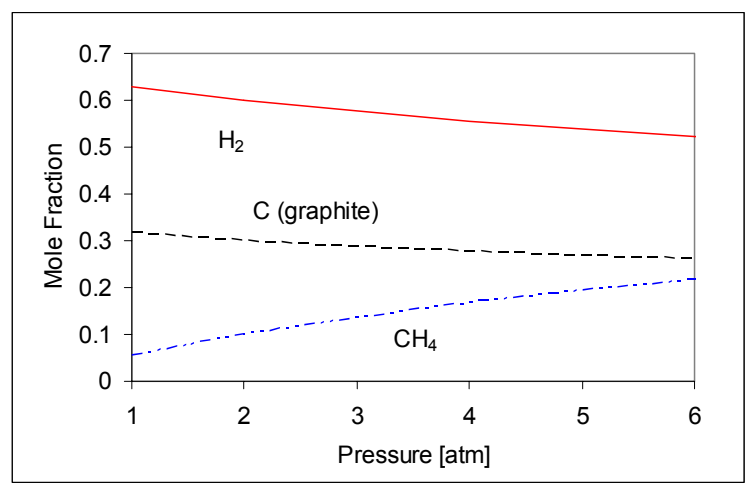

Fig. 2. Computed mole fractions for methane pyrolysis at $1000 \mathrm{~K}$ for pressures from 1 to $6 \mathrm{~atm}$.

\section{Methane Pyrolysis}

Although the plasma process for methane pyrolysis is a non-equilibrium one, a preliminary analysis of methane pyrolysis was performed using the NASA CEA code for temperatures of $1000-4500 \mathrm{~K}$ and for a range of pressures that are accessible in UTA's arc heater facility. ${ }^{30}$ This preliminary analysis provided a qualitative indication of what may be expected in the experiment. The analysis showed that a low-temperature plasma of 1000 $\mathrm{K}$ will pyrolyze methane into molecular hydrogen and carbon without significant presence of other species such as acetylene or atomic hydrogen. The calculations at $1000 \mathrm{~K}$ are shown in Fig. 2. The figure indicates that the maximum hydrogen yield occurs at low pressures. It also indicates that some of the methane remains unconverted.

\section{Test Facility}

\section{Arc Heater Test Facility}

The experiments were performed in a 1.6 .6 MW DC electric arc heater facility. The Huels-type arc heater (Thermal Dynamics Model F-5000) utilizes a vortexstabilized, high voltage, moderate pressure DC electric arc. ${ }^{31}$ A schematic of the arc heater facility configured for aerodynamics testing is shown in Fig. 3. Further details of the facility, including operational characteristics, are found in Ref. 32. The total pressure and total enthalpy capability of the facility is shown for nitrogen as the test gas in Fig. 4. 


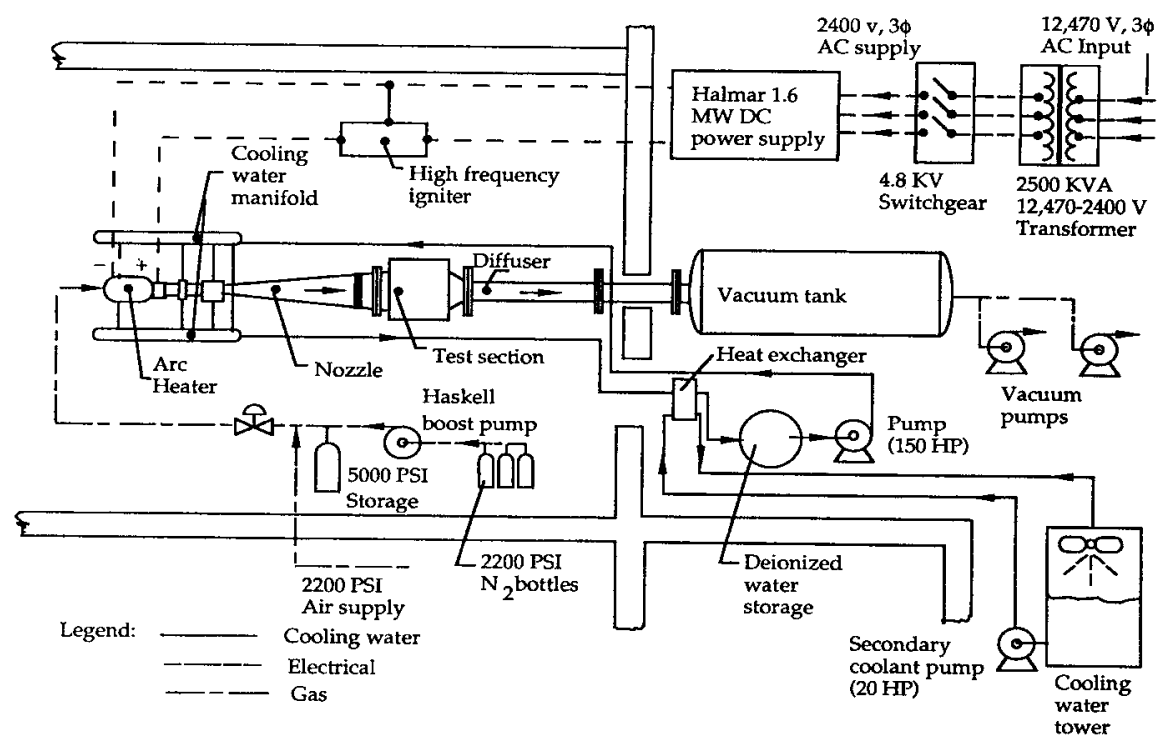

Fig. 3. Schematic of arc heater facility.

The arc heater facility was operated using nitrogen prior to the methane pyrolysis experiments. The arc heater is started with argon flow. The nominal $2650 \mathrm{~V}$ open circuit potential was sufficient to initiate breakdown of the argon, and as soon as the arc is struck, the gas flow was rapidly switched to nitrogen.

Nitrogen was introduced into the arc chamber through tangential injection slots, thus forming an intense vortical flow that centered the arc column. The arc is stretched from a tungsten cylinder at the base of the cathode barrel through the anode barrel and into the plenum chamber. The expansion of the gas into the plenum chamber reduced the strength of the vortex, thus allowing the arc to attach to the copper surface. However, sufficient residual vorticity was present to cause the arc attachment point to rotate, thus preventing attachment at a single location that might cause a burnthrough to the cooling water passages.

The same approach in initiating the arc with argon was used in the methane reformation experiments. Assuming no change in efficiency, the same mass flow in methane will be achieved at an increase in pressure by 1.75 compared to nitrogen since the ratio of the gas constant of nitrogen to methane is 1.75 . Thus, with the arc heater operating on methane, a first-order estimate of the chamber pressure is $4.8 \mathrm{~atm}$. However, the nominal test conditions were arc current and voltage of $500 \mathrm{~A}$ and $880 \mathrm{~V}$ respectively, yielding a nominal power of 440 $\mathrm{kW}$. The gas stagnation enthalpy was approximately 4.5 $\mathrm{MJ} / \mathrm{kg}$, the chamber pressure was approximately $3.5 \mathrm{~atm}$ and the mass flow was $0.11 \mathrm{~kg} / \mathrm{s}$. The nozzle ensured a flow at low supersonic Mach number to enter the test cabin. The test conditions simulate conditions expected

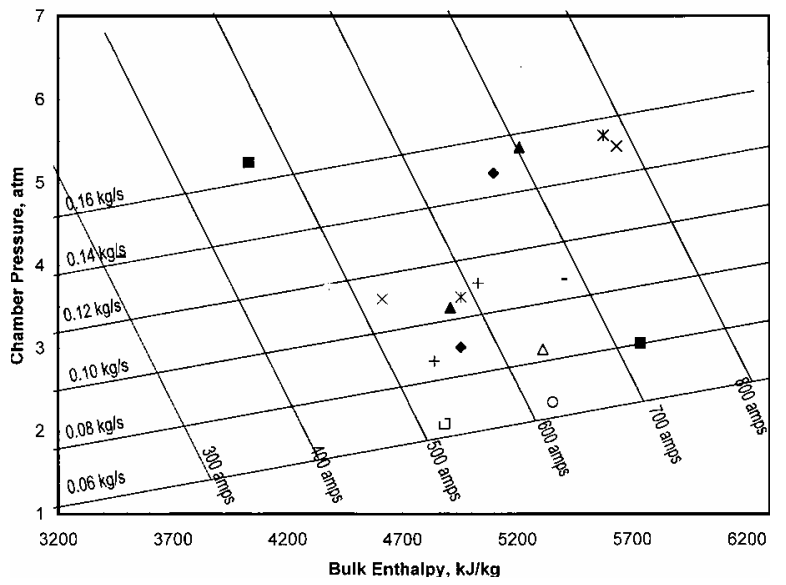

Fig. 4. Arc heater performance map with nitrogen.

at the fuel reformer of representative hypersonic airbreathing flight conditions.

Several modifications to the arc heater facility were required to switch from nitrogen to methane operation, and are summarized below. It should be noted that operating the facility at elevated pressure means a reduction in hydrogen yield, as indicated from Fig. 2.

\section{Gas Injection System}

The operational technique of starting a run with argon for 1 to $2 \mathrm{~s}$ and then switching to the test gas, in this case, methane, was maintained. Additional plumbing lines from a remotely located methane storage, flashback arrestors and control valves were installed. The flow metering nozzle was recalibrated for methane operation. 
Various safety measures were implemented to minimize the possibility of methane leakage into the test area.

\section{Cooling Water System}

Additional piping and fittings were installed to accommodate the new diagnostic chamber. Further, cooling lines were run from the arc heater cooling water manifolds to the diagnostic chamber, carbon trap and optical probe.

\section{Vacuum System}

The existing arc heater vacuum system was used to evacuate the air from the test chamber prior to a run to minimize the possibility of fire or explosion inside the chamber. A secondary function was safely disposing of the hydrogen and other flammable products of methane pyrolysis. There does not appear to be a need to flare the exhaust. $^{33}$ An existing high capacity mechanical pump was used for initial evacuation of the test chamber. Under normal operation, the vacuum is sustained during a test run by an air ejector pump driven by high pressure air from the compressor plant.

\section{Diagnostic Chamber and Instrumentation}

A 5 in., Schedule 160 pipe (110 ID and $141 \mathrm{~mm}$ OD), $406 \mathrm{~mm}$ long, was used to fabricate the diagnostic chamber, as shown schematically in Fig. 5, was used to collect the exhaust products from the fuel reformation processes occurring in the arc heater. Pyrolytic products at supersonic conditions exit the arc heater nozzle at the left and enter the diagnostic chamber. The diagnostic chamber is equipped with various ports for probes. Gaseous species formed in the fuel reformation process, anticipated to be a mixture of $\mathrm{H}_{2}, \mathrm{CH}_{4}$, and trace amounts of various $\mathrm{CH}$ species, were sampled via emission spectroscopy. Two viewing ports were located at the entrance to the chamber for observing the spectra emitted from the arc heater exhaust plume.

In addition, a water-cooled cold trap is located at the center of the diagnostic chamber for collection of the carbon particles. The cold trap is shown in Fig. 6. The trap is $50 \mathrm{~mm}$ in diameter and $200 \mathrm{~mm}$ long. This trap was designed with two removable sections, a hollow probe and a collection cup located at the base of the probe. These can be removed after a test run for weighing the carbon deposit. The assembled diagnostic chamber is shown in Fig. 7.

\section{Preliminary Results}

A limited test was conducted with the apparatus at one test condition. The photograph in Fig. 8 shows the carbon trap totally covered with a very fine carbon powder deposit, clearly indicating that methane pyrolysis had occurred. Raman spectroscopy analysis indicates that the deposit was ordinary graphite.

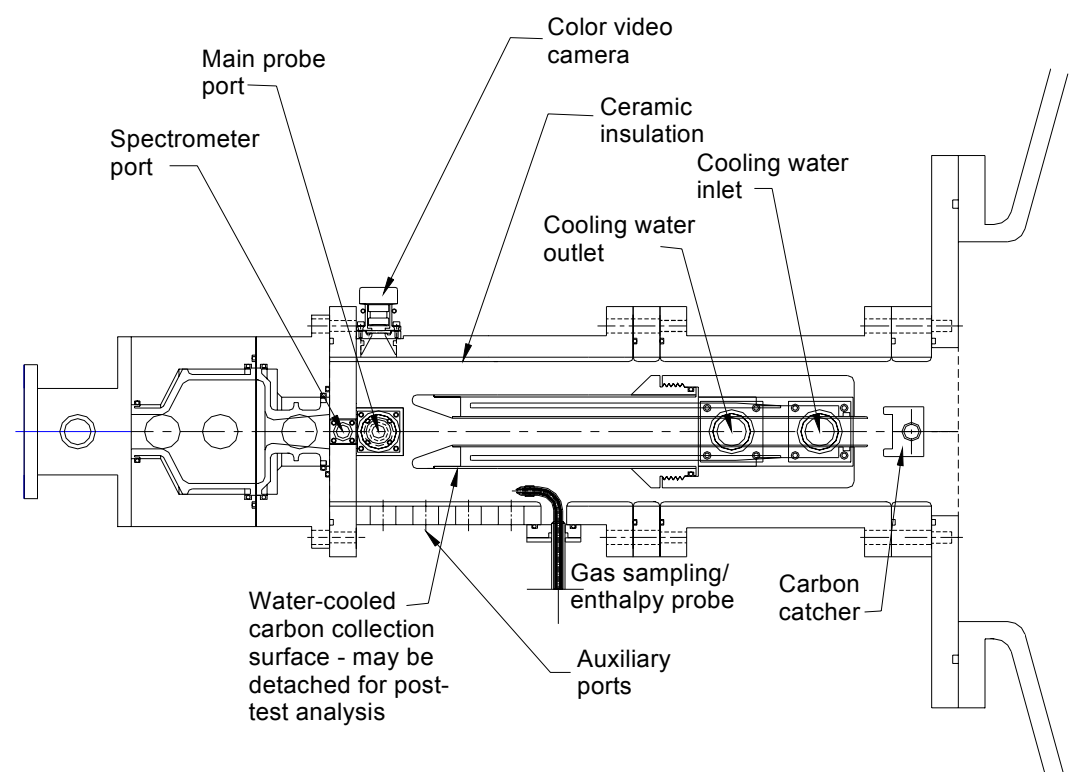

Fig. 5. Schematic of fuel reformation diagnostic chamber. 


\section{Conclusions}

An arc heated facility was modified for methane pyrolysis in a supersonic flow. Preliminary results demonstrated that pure carbon was formed.

\section{Acknowledgements}

The experimental investigation was supported by a contract from MSE, Inc. (No. 03C671CR), under the direction of Dr. Y.M. Lee. This work was part of a NASA SBIR Grant NAS1-01007. We are grateful to Prof. Suresh Sharma of the Physics Department, University of Texas at Arlington, for providing spectroscopic analysis of the carbon deposit.

\section{References}

${ }^{1}$ Gustafson, M.D. and Livingston, J.W., “An Approach Toward the Realization of Airbreathing Hypersonic Systems," AIAA Paper 2002-5142, 2002.

${ }^{2}$ Heuter, U. and McClinton, C.R., "NASA's Advanced Space Transportation Hypersonic Program," AIAA Paper 2002-5175, 2002.

${ }^{3}$ Heister, W.H. and Pratt, D.T., Hypersonic Airbreathing Propulsion, 1994, AIAA, Reston, Virginia.

${ }^{4}$ Sweetman, B., Aurora: The Pentagon's Secret Hypersonic Spyplane, Motorbooks, Osceola, Wisconsin, 1993 , p. 73.

${ }^{5}$ Bruno, C. and Czysz, P.A., "Scramjet/MHD Aeropropulsion System", AIAA Paper 98-1582, 1998.

${ }^{6}$ Czysz, P.A. and Murthy, S.N.B., (1996), "Energy Management and Vehicle Synthesis", in: Developments in High-Speed-Vehicles Propulsion Systems, ed. by S.N.B. Murthy and E.T. Curran, AIAA, Reston, Virginia, Chapter 12.

${ }^{7}$ Ogden, J.M., "Prospects for Building a Hydrogen Energy Infrastructure," Annual Review of Energy and the Environment, Vol. 24, 1999, pp. 227-279.

${ }^{8}$ Alaa-Eldin, M.A., Grace, J.R., Lim, C.J. and Elnashaie, S.S., "Fluidized Bed Reaction System for Steam/Hydrocarbon Gas Reforming to Produce Hydrogen," U.S. Patent 5,326,550, July 5, 1994.

9 Gurentsov, E., Divakov, O. and Eremin, A., "SelfIgnition of Steam Reforming of Methane Products Behind Shock Waves," Paper 1431, Proceedings of the Twenty-Third International Symposium on Shock Waves, Fort Worth, Texas

${ }^{10}$ Bruno, C. and Czysz, P.A., "Magnetohydrodynamic Coupled Ramjet Propulsion System: A Perspective," ISABE-2001-1230, $15^{\text {th }}$ International Symposium on Air Breathing Engines, Bangalore, India, September 2001.

${ }^{11}$ Muradov, N.Z., "How to Produce Hydrogen from Fossil Fuels Without $\mathrm{CO}_{2}$ Emission," International Journal of Hydrogen Energy, Vol. 18, No. 3, 1993, pp.

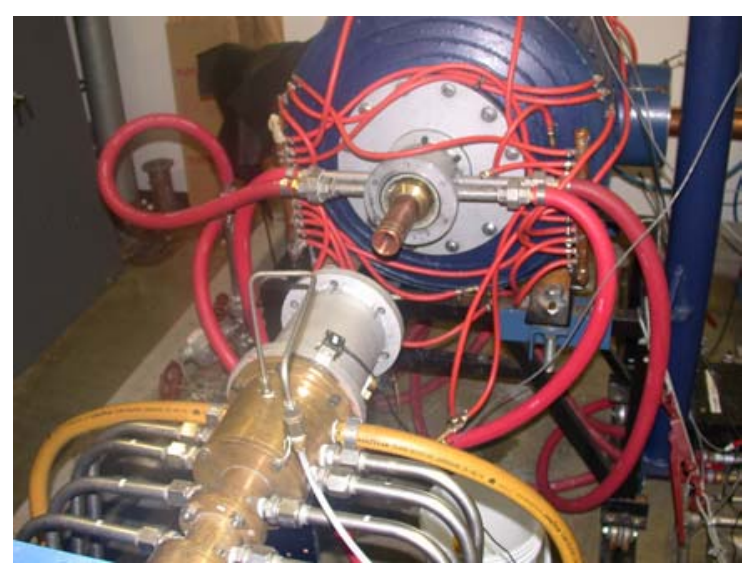

Fig. 6. Photograph of diagnostic chamber showing carbon cold trap.

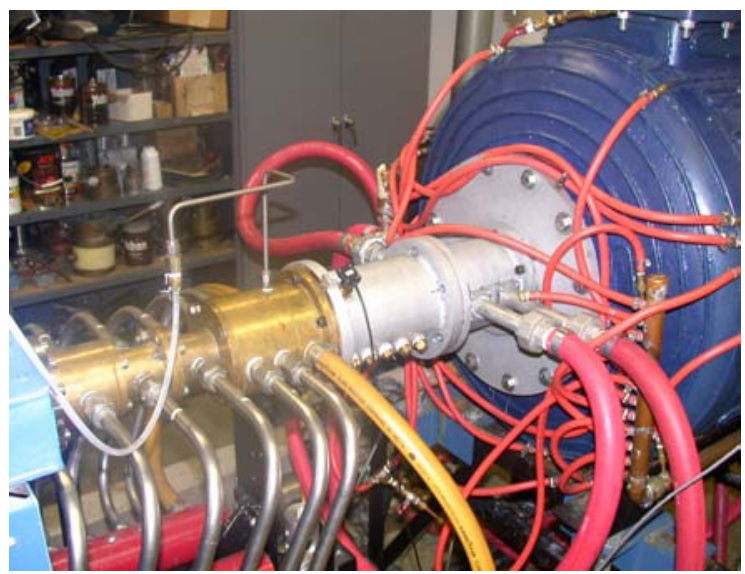

Fig. 7. Photograph of assembled diagnostic chamber.

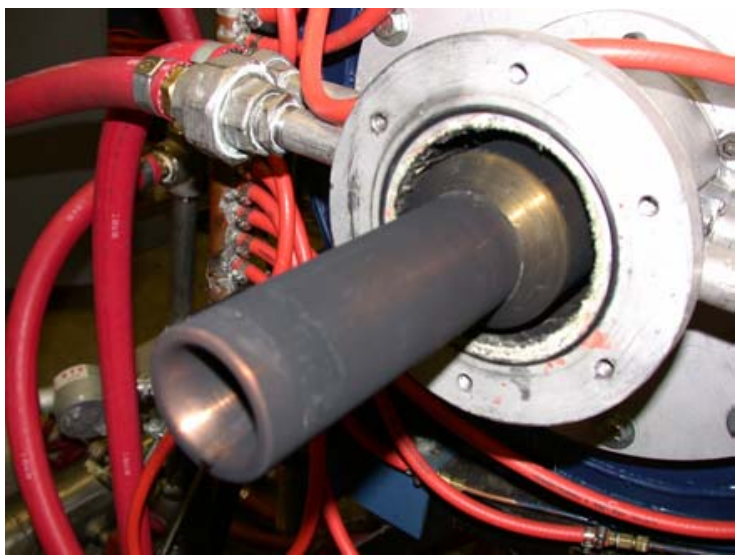

Fig. 8. Carbon deposition resulting from methane pyrolysis.

211-215.

${ }^{12}$ Kim, M.H., Lee, E.K., Jun, J.H., Kong, S.J., Han, 
G.Y., Lee, B.K., Lee, T.-J. and Yoon, K.J., "Hydrogen Production by Catalytic Decomposition of Methane over Activated Carbons: Kinetic Study," International Journal of Hydrogen Energy, Vol. 29, No. 2, 2004, pp. 187-193.

${ }^{13}$ Lynum, S., Hugdahl, J. and Hildrum, R., "The Kvaerner Process," paper presented at Carbon Black World, Nice, France, March 4-6, 1996.

${ }^{14}$ Fulcheri, L. and Schwob, Y., "From Methane to Hydrogen, Carbon Black and Water," International Journal of Hydrogen Energy, Vol. 20, No. 3, 1995, pp. 197-202.

${ }^{15}$ Gaudernack, B. and Lynum, S., "Hydrogen From Natural Gas Without Release of $\mathrm{CO}_{2}$ to the Atmosphere," International Journal of Hydrogen Energy, Vol. 23, No. 12, 1998, pp. 1087-1093.

${ }^{16}$ Nozaki, T. Kimura, Y., Okazaki, K., "Carbon Nanotubes Deposition in Glow Barrier Discharge Enhanced Catalytic CVD," Journal of Physics D: Applied Physics, Vol. 35, No. 21, 2002, pp. 2779-2784.

${ }^{17}$ Palm, T., Buch, C., Kruse, B., Sauar, E., "Green Heat and Power," Bellona Report 3:1999, (English version, June 2000, http://www.bellona.no/en/energy/report_31999/31161.html)

${ }^{18}$ Bromberg, L., Cohn, D.R. and Rabinovich, A., "Plasma Reformer-Fuel Cell System for Decentralized Power Applications," International Journal of Hydrogen Energy, Vol. 22, No. 1, 1997, pp. 83-94.

${ }^{19}$ Bromberg, L., Cohn, D.R., Rabinovich, A. and Alexeev, N., "Plasma Catalytic Reforming of Methane," International Journal of Hydrogen Energy, Vol. 24, No. 12, 1999, pp. 1131-1137.

${ }^{20}$ Cohn, D.R., Rabinovich, A., Titus, C.H. and Bromberg, L., "Near-Term Possibilities for Extremely Low Emission Vehicles Using Onboard Plasmatron Generation of Hydrogen," International Journal of Hydrogen Energy, Vol. 22, No. 7, 1997, pp. 715-723.

${ }^{21}$ Rusu, I. and Cormier, J.-M., "Study of a Rotarc Plasma Reactor Stability by Means of Electric Discharge Frequency Analysis," International Journal of Hydrogen Energy, Vol. 28, No. 10, 2003, pp. 1039-1043.

${ }^{22}$ Cormier, J.-M. and Rusu, I., "Syngas Production via Methane Steam Reforming With Oxygen: Plasma Reactors Versus Chemical Reactors," Journal of Physics D: Applied Physics, Vol. 34, No. 18, pp. 2798-2803.

${ }^{23}$ Fridman, A., Nestor, S., Kennedy, L.A., Saveliev, A. and Yardimci, O., "Gliding Arc Gas Discharge," Progress in Energy and Combustion Sciences, Vol. 25, No. 2, 1999, pp. 211-231.

${ }^{24}$ Sobacchi, M.G., Saveliev, A.V., Fridman, A.A., Kennedy, L.A., Ahmed, S. and Krause, T., "Experimental Assessment of a Combined Plasma/ Catalytic System for Hydrogen Production via Partial Oxidation of Hydrocarbon Fuels", International Journal of Hydrogen Energy, Vol. 27, No. 6, 2002, pp. 635-642.

${ }^{25}$ Korabelnikov, A.V. and Kuranov, A.L., "Thermo- chemical Conversion of Hydrocarbon Fuel Under the Concept 'AJAX,"'AIAA Paper 99-4921, 1999.

${ }^{26}$ Kuranov, A.L., Korabelnikov, A.V., Kuchinsky, V.V. and Sheikin, E.G., "Fundamental Techniques of the AJAX Concept," AIAA Paper 2001-1915, 2001.

${ }^{27}$ Bityurin, V.A., Zeigarnic, V.A. and Kuranov, A.L., "On a Perspective of MHD Technology in Aerospace Applications," AIAA Paper 96-2355, 1996.

${ }^{28}$ Bruno, C. and Czysz, P.A., "An Electro-MagneticChemical Hypersonic Propulsion System," AIAA Paper 98-1582, 1998.

${ }^{29}$ Lee, Y.-M., Czysz, P.A. and Petley, D., "Magnetohydrodynamic Energy Bypass Applications for Single Stage-to-Orbit Vehicles." AIAA Paper 20011901, 2001.

${ }^{30}$ Gordon S. and McBride B., "Computer Program for Calculation of Complex Chemical Equilibrium Compositions and Applications, I. Analysis," NASA RP 1311, October 1994

(http://www.grc.nasa.gov/WWW/CEAWeb/).

${ }^{31}$ Smith, D.M., Felderman, E.J., Shope, F.L. and Balboni, J.A., "Arc-Heated Facilities," Chapter 10 in Advanced Hypersonic Test Facilities, ed. by F.K. Lu and D.E. Marren, AIAA, Reston, Virginia, 2002.

${ }^{32}$ Boonjue, S.B., Roseberry, C.M. and Wilson, D.R., "Results from Initial Operation of a Continuous-Flow, Arc-Heated Hypersonic Propulsion Test Facility," AIAA Paper-96-4505, 1996.

${ }^{33}$ Garrard, G. and Bartlett, C., "Hydrogen Exhaust Gas Disposition by Afterburning." AIAA Paper 91-5075. 